\title{
The Multidimensional Education Quality Evaluation System for the Master of Engineering
}

\author{
Kaikun Dong, Dianhui Chu*, Li Guo, Kuanquan Wang \\ School of Computer Science and Technology \\ Harbin Institute of Technology at Weihai \\ Weihai, China \\ kaikun.dong@gmail.com
}

\begin{abstract}
Quality is the lifeline of the education of Master of Engineering. In this paper, the quality problems in the education of Master of Engineering in China are introduced and discussed briefly. Then the Engineering Education Accreditation and its education quality evaluation methods are introduced, and the strengths of these methods are analyzed and summarized. Based on the ideas and evaluation framework of the Engineering Education Accreditation, adopting the merits of Chinese traditional education quality evaluation methods, a multidimensional education quality evaluation system for the Master of Engineering is proposed in the purpose of continuous quality improvement and educational goals achievement. The evaluation system covers educational goals, students , development, course system, industrial practice, dissertation, supporting conditions and continuous improvement, totally seven dimensions. Student centered cultivation, outcomes-based education, and continuous quality improvement are the core philosophies of the proposed education quality evaluation system.
\end{abstract}

Keywords-Education quality evaluation; Master of Engineering; Engineering Education Accreditation; Continuous improvement

\section{INTRODUCTION}

Since the education of Master of Engineering (ME) was approved by the Academic Degrees Committee of the State Council in 1997, the education of ME in China has experienced 20 years. Up to now, the education of ME has been carried out in 40 engineering fields. There are 3387 educational organizations of 407 universities have been approved to recruit postgraduate students of ME. A large number of technical and technical management talents have been trained for the enterprises and institutions all over the country. The education of ME has become one of the most important ways for the training of high level personnel of engineering [1]. However, along with the extremely increasing development of the education of ME, some quality problems have also arisen in a number of educational organizations. Therefore, more and more attentions from the education organizations, governments, industry and the public have been paid to the postgraduate education quality of ME [2].

- The course system has no much characteristics of engineering. In some universities, the course system of ME overlaps much the course system of the academic Master of the same discipline. The course contents, teaching methods and teachers are similar to each other. In many cases, the two categories of postgraduate students study the same course together.

- The quality of industrial practice is not high [3]. In some universities, steady-going practice bases have not been established and no strict regulations have been set up to check and evaluate the quality of student's industrial practice and the quality of the bases' running. Some students didn't participate in an industrial practice before graduation. Some students just take the industrial practice as practical experience before employment and no high quality of engineering tasks have been accomplished.

- In some universities, the quantity and quality of faculty and other supporting conditions cannot meet the rapid growth of the number of students.

- The dissertations of ME in some universities lack of engineering characteristics. The topics of the dissertations are influenced markedly by the supervisor's scientific research. If a supervisor has undertaken a project of National Science Foundation, a fundamental theory research topic may be assigned to a graduate student of $\mathrm{ME}$.

- Some educational organizations take the education of $\mathrm{ME}$ as a way of creating income. Therefore, the quality control is lax during the educational sections such as admission of students, course teaching and test, industrial practice, dissertation and giving degrees.

Quality is the lifeline of the education of ME. To solve the problems mentioned above, a multidimensional education quality evaluation system based on the ideas and evaluation framework of Engineering Education Accreditation is studied. The rest of the paper is organized as follows. Section 2 investigates and summarizes the strengths of the education quality evaluation method of Engineering Education Accreditation. In section 3, the multidimensional education quality evaluation system for ME is proposed and section 4 draws conclusions. 


\section{THE STRENGTHS OF THE EDUCATION QUALITY EVALUATION METHOD OF ENGINEERING EDUCATION ACCREDITATION}

On June 2, 2016, China was accepted as the 18th official member of Washington Agreement on the International Engineering Alliance Conference held in Kuala Lumpur. Although Washington Agreement is an international agreement focusing more on the mutual admission for the undergraduate degree of engineering, the concepts, ideas and educational quality evaluation system of Engineering Education Accreditation based on it also has a profound guiding significance for improving the quality of engineering education at postgraduate level. Currently, the research and working team of professional qualification accreditation and docking led by the Chinese National Supervisory Committee for the Education of Master of Engineering has proposed the Framework of the Postgraduate Level Engineering Education Accreditation. In China, the Academic Degrees Committee of the State Council, the National Ministry of Education, the Chinese National Supervisory Committee for the Education of Master of Engineering and China Engineering Education Accreditation Association are actively promoting the engineering education accreditation at postgraduate level.

What is Engineering Education Accreditation? Literature [4] points out that the so-called accreditation is the evaluation procedure to confirm whether an education organization's educational practice can guarantee the achievement of its educational goals according to some widely accepted standards and processes. Compared with traditional education quality evaluation methods, accreditation can not only accurately evaluate the education quality of an education organization, but also promote the education reform and improve the education quality. Engineering Education Accreditation is a kind of professional accreditation. It is a procedure of evaluation, confirmation and making suggestions for improvement. The Accreditation is performed independently by a professional organization or association. Academic experts from higher education and technical experts from industry of corresponding engineering field will evaluate the education quality of an education organization in a specialty according to the vocational qualification requirements of the engineering field. The core goal of Engineering Education Accreditation is to confirm whether the engineering graduates have met the established quality standard of the industry and provided the preparatory education quality assurance for the relevant engineering and technical personnel to enter the industry. This is highly accords with the educational goal of $\mathrm{ME}$ for qualifying the postgraduates for the engineering and technical profession by cultivating their professional competency.

Professor Bloom, an American educational evaluation expert from University of Chicago, pointed out in his book "Taxonomy of Educational Objectives--Cognitive Domain" that "Educational evaluation is a systematic collection of evidence to determine whether the learner has actually been made some changes, or to determine the number or extent of the changes has been made in individuals."

The strengths of the education quality evaluation method of Engineering Education Accreditation are embodied in the following aspects.
- Emphasize goal orientation. An important idea of Engineering Education Accreditation is orienting the educational practice to the student educational goals and graduation requirements. All the aspects of educational practice should effectively support the achievement of educational goals for students.

- Student-centered and focusing on educational output and effectiveness. The ultimate educational goal of education activities is what the students have learned, not what the teachers have taught. Education activities should promote the students' knowledge accumulation and cognitive ability. The number or extent of the promotion should be considered into the education quality evaluation system.

- Reflecting the whole process of education practice. While emphasizing the educational output and effectiveness, Engineering Education Accreditation also focuses on the whole process of education. As the most important participant in education, the students' performance should be adopted as the indicators of the education quality evaluation system.

- Paying attention to the educational supporting conditions. The educational supporting conditions of the educational organizations are required by the Engineering Education Accreditation to be conducive to help the students to achieve the expectant educational goals.

- Emphasizing continuous improvement. The main educational sections should have clear quality requirements and evaluation mechanisms, and the evaluation results should be used for continuous education quality improvement.

\section{THE MULTIDIMENSIONAL EDUCATION QUALITY EVALUATION SYSTEM BASED ON ENGINEERING EDUCATION ACCREDITATION}

In China, the traditional education quality evaluation methods usually focus on the performance of the faculty and the supporting conditions of the universities. Therefore, these methods can significantly promote the improvement of teacher's teaching and universities' infrastructure and facilities. However, the performance and development of students have not gained full attention.

Based on the ideas and evaluation framework of Engineering Education Accreditation, adopting the merits of traditional education quality evaluation methods, a studentcentered education quality evaluation system is proposed in order to evaluate objectively and accurately the education quality of $\mathrm{ME}$, promote the continuous education quality improvement and ensure the achievement of the students educational goals [5-6]. The evaluation system covers educational goals, student development, course system, industrial practice, dissertation, supporting conditions and continuous improvement, totally seven dimensions, as shown in Fig. 1. 


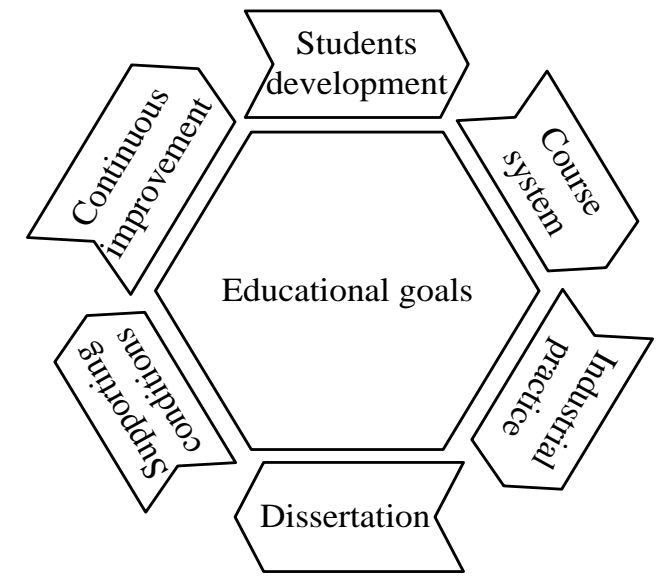

Fig. 1. The multidimensional education quality evaluation system for the Master of Engineering

Educational goals are broad statements that describe what graduates are expected to attain within a few years after graduation. Public educational goals meeting the requirements from the Academic Degrees Committee of the State Council should be set up by the educational organizations.

Student development. Student performance must be assessed. Student cultivation progress must be monitored to ensure the attainment of student learning outcomes and further the educational goals. Students must be advised and guided regarding curriculum and career matters. The educational organizations must have and enforce procedures to ensure and document that students who graduate meet all graduation requirements.

The course system requirements specify the knowledge, professional skills and abilities appropriate to the corresponding engineering fields. It is not necessary for the educational organizations to provide just the same courses. Educational organizations must guarantee their faculty spending enough attention and time on all the components supporting the educational outcomes and goals. The professional component must include:

- Master level mathematics, basic nature sciences, necessary social sciences appropriate to the engineering fields and foreign language.

- Engineering technologies, including general engineering sciences and engineering design methods appropriate to the postgraduate's engineering field. The general engineering sciences are based on mathematics and basic nature sciences, and closely related to engineering application. The engineering technology education builds a bridge between mathematics, basic sciences and engineering application. Engineering design methods are the process of constructing a product, system, component, or process to meet the engineering practice needs. The mathematics, nature sciences, social sciences, general engineering sciences and engineering design methods are used for solving the complex engineering problems under uncertain environments.
- Other components that supplement the course system and meet the graduation requirements, organization objectives and society needs.

Students should be adequately prepared for industrial practice through some practice courses fostering professional engineering design experience. The knowledge and skills learned from the course system should be synthetically applied in the practice courses.

Adequate master's level industrial practice should be completed to support the training of professional competency. The industrial practice should be guided jointly by the tutors from universities and technical experts from industry of corresponding engineering field. The quality and outcomes of industrial practice must be assessed and evaluated according to the graduation requirements.

The dissertation topic of ME students must have explicit engineering backgrounds and significance. The research production of an ME dissertation could be applied directly or indirectly in engineering practice. The workload and difficulty of the ME dissertations must meet the requirements of Master Degree.

Supporting conditions requirements. Classrooms, laboratories, associated instruments and equipments must be adequate to support the attainment of the ME postgraduate students outcomes. Modern tools, equipments, computing resources, and laboratories needed in the education of $\mathrm{ME}$ postgraduate students must be fully guaranteed to ensure the attainment of the student outcomes and educational goals. Postgraduate students must be provided appropriate guidance regarding the use of the tools, instruments, equipments, computing resources, and laboratories. The library, the computing and information infrastructures should be adequate to support the education of the ME postgraduate students.

The education organization must ensure that the faculty members and their abilities, competencies and professional experience are adequate to provide Mater level student-faculty interaction, student advising and counseling, and professional development. The faculty with industry working experience and experts from industry should participate in the supporting of student development.

The faculty must have sufficient qualifications and authority to provide adequate and proper guidance of the $\mathrm{ME}$ postgraduate students. The faculty should develop and implement processes for the teaching quality evaluation and assessment. And the evaluation results must be utilized in the continuous quality improvement of the teaching activities and the educational organization.

The overall competence of the faculty should be assessed by their education backgrounds, engineering communication abilities and experience, enthusiasm for teaching and education, devotion of teaching research, participation in professional association and societies.

University, school or department support and leadership must be guaranteed to ensure the educational quality and continuity of the education. Resources including institutional services, financial support, technical and administrative staff 
must be adequate to provide enough educational supporting and satisfy educational needs. The resources should be available, accessible, and systematically maintained to support the professional development of a qualified faculty and the student cultivation.

Continuous quality improvement. Regular and documented processes should be carried out to assess and evaluate the quantity and extent of the educational outcomes being attained. The evaluation results must be used for continuous education quality improvement and the setting up of a closed-loop education quality control process.

\section{CONCLUSIONS}

The proposer of CIPP (Context, Input, Process, Product evaluation) evaluation model, Daniel L. Stufflebeam pointed out that the most important purpose of evaluation is not to prove, but to improve [7]. The key point of education quality evaluation for ME postgraduates should be identifying the problems and shortcomings existed in the education process and the effective problem solving methods. The quality evaluation ought to be applied for the education quality improvement. Based on the ideas and evaluation framework of Engineering Education Accreditation, adopting the merits of traditional classroom teaching quality evaluation methods, a multidimensional education quality evaluation system for the $\mathrm{ME}$ is proposed to evaluate and continuously improve the education quality. At present, this research is still in the exploratory stage, and need more in-depth research, especially the confirmation of evaluation practice for further improvement.

\section{ACKNOWLEDGMENT}

This research was supported by the Chinese National Supervisory Committee for the Education of Master of Engineering under Grant No. 2016-ZDn-6, the Academic Degrees and Graduate Education Department of the Chinese National Ministry of Education under Grant No. 2014-ZDn-07, Shandong Provincial Department of Education under Grant No. SDYY14003 and No. SDYZ1603.

\section{REFERENCES}

[1] Y. Shen, Y. Qin, Y. Gao, and K. He. "Promoting comprehensive reform, innovating cultivation model, improving education quality and satisfying needs-Summary of the comprehensive reform pilot of the Engineering Master Degree postgraduate students' education," Academic Degrees and Graduate Education, Beijing, vol. 2, pp. 5-8, February 2014. (In Chinese)

[2] B. Huang, W. Xu, Y. Zhang, and T. Hao. "Accelerating the improvement of the national academic degree and postgraduate education quality assurance and supervision system," Academic Degrees and Graduate Education, Beijing, vol. 3, pp. 1-9, March 2014. (In Chinese)

[3] K. Dong, K. Wang, S. Luo, et al. "The interpretation of the basic standard for the professional master degree of engineering in computer technology field," Academic Degrees and Graduate Education, Beijing, vol. 3, pp. 59-64, March 2017. (In Chinese)

[4] N. Kohli. "Role of accreditation in engineering education," Proceeding of the IEEE International Conf. On MOOC, Innovation and Technology in Education. New York: IEEE Press, 2014, pp. 157-159.

[5] K. Dong, K. Wang, P. Song, S. Luo, and H. Liu. "The construction of a classroom teaching quality evaluation system for the Master of Engineering-Taking computer technology field as example" Computer Education, Beijing, vol. 273, pp. 69-73, September 2017. (In Chinese)

[6] K. Dong, K. Wang, L. Guo, and M. Guo. "An Internal Quality Assurance System for the Education of Master of Engineering in Computer Technology Field," Proceeding of the 6th Annual International Conf. on Computer Science Education: Innovation and Technology. Singapore: Global Science and Technology Forum, 2015, pp. 85-88.

[7] D. L. Stufflebeam, F. Madaus, and Thomas Kellagha. "Evaluation Models: Viewpoints on Educational and Human Services Evaluation (Second Edition). Peking University Press, 2007. 